Revista de

Contabilidade e

Organizações

www.rco.usp.br
DOI: http://dx.doi.org/10.11606/issn.1982-6486.rco.2019.158709
Journal of

Accounting and

Organizations

\title{
Gerenciamento de riscos à reputação no discurso dos relatórios corporativos da Samarco
}

\author{
Reputation risk management on the discourse of Samarco corporate reports
}

José Alex Nobrega de Oliveira ${ }^{\mathrm{a}}$, Yara Consuelo Cintra ${ }^{\mathrm{a}}$

${ }^{a}$ Universidade Federal do Rio de Janeiro

Palavras-chave

Reputation risk management. RRM.

Legitimidade.

Samarco.

\section{Resumo}

O objetivo desta pesquisa é investigar a influência do reputation risk management (RRM) sobre o disclosure de relatórios corporativos, em especial dos relatórios de sustentabilidade. Foram analisados os relatórios da mineradora Samarco responsável pela barragem de Fundão, em Mariana, Minas Gerais, Brasil, objeto do acidente ocorrido em novembro de 2015. O período avaliado foi 2010 a 2016, tendo o último relatório contemplado o desastre e seus impactos ambientais e sociais. A análise de conteúdo dos relatórios sugere uso dos relatórios socioambientais como instrumento de RRM por meio da análise de elementos de reputação selecionados e da aplicação de uma tipologia de restauração de imagem. Os achados contribuem para a compreensão dos determinantes do disclosure socioambiental, ampliando o espectro da teoria da legitimidade, agregando a componente reputação e o gerenciamento de riscos à reputação.

\begin{abstract}
The objective of this research is to investigate the influence of reputation risk management (RRM) on the disclosure of corporate reports, especially sustainability reports. The study analysed reports of Samarco - mining company responsible for the Fundão dam in Mariana, Minas Gerais, Brazil, object of the accident occurred in November 2015. The period comprised 2010 to 2016, the latter covering the disaster and its social and environmental impacts. The content analysis of the reports suggests the use of social and environmental reports as an RRM tool by analyzing selected reputation elements and applying an image restoration typology. The findings contribute to the understanding of the determinants of socio-environmental disclosure, broadening the spectrum of legitimacy theory, adding the reputation component and risk management to reputation.
\end{abstract}

\section{Implicações práticas}

A presente pesquisa mostra que os relatórios de sustentabilidade são capazes de influenciar a reputação das empresas. Tal fato, pode encorajar maior divulgação por parte das empresas, aumentando o nível de informação e proporcionando maior transparência sobre as ações adotadas pelas empresas. 


\section{INTRODUÇÃO}

Nos últimos vinte anos, houve mundialmente um aumento relevante na produção de relatórios socioambientais ou de responsabilidade social corporativa. Esses relatórios assumem formas diversas, sendo atualmente mais conhecidos como 'relatórios de sustentabilidade', que na maioria dos países constituem evidenciações voluntárias e têm sido objeto frequente de investigação acadêmica (Lozano \& Huisingh, 2016).

Deegan (2002) compilou os principais motivos que levam as empresas a divulgar informação socioambiental: cumprir requisitos legais; considerações de racionalidade econômica; reconhecimento do direito inalienável dos leitores à informação; atender às expectativas da comunidade; responder às ameaças à legitimidade da organização; gerir grupos poderosos de stakeholders; atrair investimento responsável; cumprir exigências de natureza industrial ou códigos de conduta específicos; evitar regulamentação de divulgação mais onerososa; ganhar prêmios específicos por seus relatos.

Gray, Owen eAdams (1996) entendem que a divulgação de responsabilidade social melhora a accountability. Em contraponto, o relatório socioambiental pode ser utilizado para atender às necessidades da instituição emissora, em detrimento do conjunto amplo de stakeholders, de maneira que seu potencial de accountability pode resultar limitado (Bebbington, Larrinaga \& Moneva, 2008; Cho et al., 2015).

Sendo a reputação um ativo intangível capaz de gerar valor (Roberts \& Dowling, 2002), é razoável supor que tenha potencial para influenciar o disclosure, isto é, a evidenciação ou divulgação de informações. Os relatórios socioambientais constituiriam parte dos processos de reputation risk management (RRM) ou gerenciamento de riscos à reputação, em tradução livre. Bebbington, Larrinaga e Moneva (2008) consideram tal relação intuitiva, mas pouco explorada na literatura de contabilidade socioambiental.

Nesse sentido, o artigo discute o imbricado panorama da teoria da legitimidade, reputação e imagem. A teoria da legitimidade tem bases sobre a noção de contrato social. Estando em conformidade com as expectativas de um ambiente social, as empresas são reconhecidas como legítimas, recebendo sua 'licença de operação'. Tal condição, contudo, é dinâmica, demandando esforços das empresas para o equilíbrio e legitimidade almejados. De longa data, a literatura vem reconhecendo o papel da comunicação e dos relatórios sociais, ou seja, do disclosure, nesse contexto (Patten, 1991; Bice, 2014).

Em cinco de novembro de 2015, o rompimento de uma barragem da Samarco Mineradora S.A., no município de Mariana/MG, causou o maior desastre ambiental do Brasil até então. Com o rompimento da barragem de Fundão e o deslocamento da barragem de Santarém, uma onda de lama aniquilou o município de Bento Rodrigues e a enorme quantidade de rejeitos sólidos acarretou sérios problemas em mais sete distritos do Município de Mariana, tendo posteriormente atingido outros estados. Além dos impactos ambientais, houve a destruição de residências, infraestrutura e de áreas de pastagem, roças e floresta, a morte de animais domésticos e silvestres, e a perda de vidas humanas com 19 vítimas fatais do acidente (Serra, 2018; Wanderley et al., 2016).

O objetivo desta pesquisa é investigar a influência do RRM sobre o disclosure de relatórios corporativos, em especial dos relatórios de sustentabilidade. A Samarco foi escolhida para análise, em virtude do acidente de Mariana, que gerou graves danos sociais, ambientais e financeiros e, como resultado, a organização pode estar sensível em relação à sua reputação. Foi realizada a análise do conteúdo dos relatórios de sustentabilidade divulgados no período de 2010 a 2016, bem como a aplicação da tipologia de restauração de imagem desenvolvida por Benoit (1995), nos moldes de Bebbington, Larrinaga e Moneva (2008) e Arora e Lodhia (2017), buscando identificar componentes do gerenciamento de riscos à reputação nos relatórios.

A presente pesquisa visa contribuir para a literatura nas dimensões teórica, metodológica e prática. Em termos teórico-conceituais, o presente estudo busca desenvolver a proposição de Bebbington, Larrinaga e Moneva (2008, p. 338) de que o gerenciamento de riscos à reputação é capaz de "colocar carne nos ossos da teoria da legitimidade", ou seja, preencher lacunas da teoria da legitimidade. O artigo apresenta um método de análise esquemático para comparação dos resultados e a teoria de base. Do ponto de vista prático, a pesquisa visa encorajar as organizações a engajar em maior transparência e accountability em sua busca por reputação e legitimidade (Larkin, 2003). 


\section{REFERENCIAL TEÓRICO}

\subsection{Legitimidade e reputação}

Na literatura de contabilidade socioambiental, a teoria da legitimidade aparece como uma das principais bases teóricas para compreensão e justificativa do comportamento corporativo, incluindo o disclosure (Deegan, 2002; Deegan, Rankin \& Tobin, 2002; Eugenio, Lourenço \& Morais, 2010; Kuruppu, Milne \& Tilt, 2019; Milne \& Patten, 2002). A teoria propõe que a organização busca direcionar a percepção do público, por meio das ações de seus gerentes, de maneira que suas atividades sejam consideradas em conformidade com os valores sociais e a empresa, vista como legítima. Nesse contexto, o disclosure socioambiental se justifica como forma utilizada pela organização para gerenciar estrategicamente seus stakeholders e obter legitimidade (Deegan, 2002).

A teoria da legitimidade foi utilizada no estudo realizado por Wink (2012), que analisa a reação de uma determinada empresa do setor de mineração brasileiro em termos de divulgação de relatórios contábeis como forma de legitimação, em virtude de notícias de acidentes ocorridos. Outras pesquisas têm mostrado que a busca pela manutenção do contrato social tem produzido impacto nos relatórios emitidos pelas empresas após a ocorrência de acidente ambiental (Cho, 2009; Patten, 1992; Pellegrino \& Lodhia, 2012; Sancovschi \& Silva, 2006).

Bebbington, Larrinaga e Moneva (2008) questionam o poder explicativo da teoria da legitimidade, propondo que a tese do RRM forneceria uma ótica mais refinada para explicar o disclosure socioambiental. Usam a hipótese de a reputação ser o fator impulsionador dos relatórios e propõem que se faça a análise do disclosure como parte do processo de gerenciamento de riscos à reputação. Unerman (2008), na mesma linha, afirma que a primordial motivação por parte dos emitentes de relatórios é a redução dos riscos à reputação.

Bebbington, Larrinaga e Moneva (2008) mencionam a dificuldade que os pesquisadores têm em distinguir reputação e legitimidade, utilizando até os termos de maneira intercambiável. Suchman (1995) destaca o caráter de construto social da legitimidade e a classifica em três diferentes tipos (pragmática, moral e cognitiva), bem como delineia os diferentes esforços e estratégias das empresas para ganhar, manter ou reparar legitimidade. $\mathrm{O}$ autor lista a construção de reputação como uma estratégia para ganho de legitimidade no tipo pragmático.

Deephouse e Carter (2005, p. 331) entendem que a legitimidade se baseia em "reunir e aderir às expectativas das normas do sistema social, regras e significados; a reputação se refere a uma comparação de organizações para determinar a sua posição relativa". Kuruppu e Milne (2014) concluem que a reputação é um ativo gerenciável por meio de ação direta, especialmente durante incidentes negativos, enquanto a legitimidade é um status social mais abrangente que exige que as empresas estejam em conformidade com valores sociais mais amplos e referenciais legais. O Quadro 1 apresenta diferenças entre reputação e legitimidade, sob a perspectiva das ações requeridas das empresas.

\begin{tabular}{ll}
\hline Legitimidade & Reputação \\
\hline Ações de longo prazo & Ações imediatas \\
Resposta de longo prazo & Resposta direta \\
Foco na própria organização & Comparação entre organizações \\
Status social amplo & Ativo mensurável \\
\hline
\end{tabular}

Quadro 1. Diferenças entre legitimidade e reputação

Fonte: Arora e Lodhia (2017, p. 1288).

\subsection{Reputation risk management e disclosure}

Os riscos operacionais fazem parte do funcionamento dos processos de negócios de rotina e do modo como as pessoas associadas a esses processos se comportam (Larkin, 2003). Daí surge a importância do gerenciamento de riscos, que envolve a prevenção, redução ou controle de riscos potenciais ou atuais. A gestão de riscos está preocupada com a avaliação e mitigação dos efeitos da volatilidade financeira, problemas de dívidas incobráveis e de liquidez, mas também avaliar riscos específicos para os mercados ou indústrias em que uma empresa opera. Indagados sobre o risco que mais os preocupa, grande parte dos empresários menciona os riscos sobre a reputação (Bebbington, Larrinaga \& Moneva, 2008). 
Sob o aspecto da reputação relacionado ao conceito de imagem corporativa, Thomaz e Brito (2010) formularam a hipótese de que os diversos stakeholders atribuem praticamente a mesma importância à reputação, concluindo que, embora cada grupo de stakeholders perceba de maneira diferente como a reputação é formada, acabam por lhe atribuir a mesma importância. Larkin (2003, p.1) destaca que construir e manter reputação demanda cuidado, planejamento meticuloso e trabalho constante através dos anos.

Os conceitos de reputação variam de uma perspectiva voltada para gestão econômica e estratégica, a qual entende a reputação como um recurso, até uma perspectiva sociológica que vê a reputação como resultado de impressões compartilhadas socialmente a respeito de uma empresa (Fombrun \& Van Riel, 1997). Miles e Govin (2000) apresentam a reputação como consequência da responsabilidade, integridade, credibilidade e confiabilidade.

A reputação como recurso intangível de uma empresa tem o potencial de trazer vantagem estratégica, pois contribui para uma imagem favorável tanto para stakeholders internos como externos (Arora \& Lodhia, 2017). Fombrun (1996) descreveu a reputação como um ativo estratégico capaz de produzir benefícios tangíveis: preços premium para produtos; menores custos de capital e trabalho; lealdade aprimorada dos funcionários; maior abrangência na tomada de decisão e maior tolerância da sociedade em face de crises. Definiu reputação corporativa em termos de percepção passada e futura dos diversos públicos que interagem com a empresa em relação à visão deles, comparativamente às empresas concorrentes, representando um recurso capaz de trazer vantagem competitiva ou desvantagem, dependendo de suas percepções positivas ou negativas.

A reputação é contextual, isto é, diferentes organizações terão características de reputação diversas dependendo dos detalhes de sua situação (Deephouse \& Carter, 2005). A reputação, embora sendo um conceito intuitivamente atraente, constitui uma complexa característica organizacional. Isso afeta a forma como pode ser formalmente estudada, sendo os estudos de classificação de reputação (ranking) e índices de reputação a maneira mais popular de abordar a reputação corporativa, bem como grande parte do estudo acadêmico.

Análise de seis estudos de ranking de reputação realizada por Bebbington, Larrinaga e Moneva (2008) Fortune, Management Today, Financial Times, Rayner, Quociente de Reputação e Reputex Social Responsibility Ratings - revelou que eles se concentram em cinco elementos de reputação: desempenho financeiro; qualidade da gestão; desempenho socioambiental; qualidade dos funcionários; e a qualidade dos bens e serviços. Pode-se argumentar que esses aspectos, que não são mutuamente exclusivos e certamente apresentam inter-relações, são usados pelos indivíduos quando avaliam a reputação da empresa, bem como percebidos pelos gerentes como capazes de influenciar a visão da reputação na organização. Ao divulgarem informações socioambientais com ênfase nos cinco elementos da reputação durante acidentes ou em outros momentos de risco, é altamente provável que tais divulgações sejam feitas com a intenção de gerenciar a reputação. Os elementos permitem relacionar o disclosure com a perspectiva do RRM, propiciando uma análise fundamentada.

Friedman e Miles (2001) sugerem que o RRM é um dos principais impulsionadores dos relatórios socioambientais, demonstrando que a busca pela manutenção da reputação de uma empresa a tornaria mais consciente da necessidade de gerenciar uma ampla gama de riscos ambientais, sociais e éticos e mostrar que age dessa forma.

Toms (2002, p, 273), usando uma visão baseada em recursos, complementada pela teoria da sinalização de qualidade, com enfoque em uma visão econômica da reputação, discute que "a qualidade do disclosure, o poder do acionista institucional e o baixo risco estão consistentemente associados à alta reputação no ambiente corporativo", sendo a qualidade da divulgação, em especial a relacionada ao aspecto da responsabilidade socioambiental, o elemento determinante do disclosure mais recente, usado pelos rankings de reputação corporativa. Esses resultados levaram Toms (2002, pág. 276) a concluir que existe "uma forte relação entre estratégia de disclosure e reputação ambiental".

Benoit (1995) fornece o arcabouço para uma ligação conceitual entre as atividades de RRM realizadas por organizações e os discursos observáveis, como resultado da necessidade de estratégias de restauração de imagem (Quadro 2). A literatura de restauração de imagem estuda responsabilidades individuais, desculpas e subterfúgios, bem como respostas corporativas às críticas. O autor apresenta explicações sobre as respostas da Exxon, Union Carbide e Tylenol a crises consideradas prejudiciais à reputação que essas empresas enfrentaram: derramamento de óleo; descarga química de uma planta industrial que matou e mutilou um grande número de pessoas; e envenenamento de produtos que levaram a mortes de consumidores, respectivamente. Para Benoit (1995), seres humanos estão envolvidos em atividades que levam a conflitos e danos potenciais à reputação, mas eles têm uma profunda necessidade de ter e manter a reputação, daí resultando as estratégias de restauração da imagem. 
Benoit (1995, p.72) argumenta que o tipo de discurso que se observa é função de dois fatores: i) um ato "repreensível" deve ter sido cometido ou percebido como cometido por um público envolvido; ii) o o ator seja considerado responsável pelo ato reprovável pelo público relevante. Bebbington, Larrinaga e Moneva (2008) sugerem que, uma vez que esses dois fatores estejam presentes, discursos de gerenciamento de reputação ou estratégias de restauração de imagem, nos termos de Benoit, provavelmente surgirão.

\begin{tabular}{l} 
Estratégia \\
\hline $\begin{array}{l}\text { Negação (inclui a simples negação e a } \\
\text { atribuição de culpa a outrem) }\end{array}$ \\
$\begin{array}{l}\text { Evadindo a responsabilidade devido à } \\
\text { provocação anterior }\end{array}$
\end{tabular}

Não responsabilização

Acidente

Boas intenções

Reduzindo a ofensividade do evento por meio de exaltação de ações positivas

\section{Minimização}

Diferenciação

Transcendência

Ataque ao acusador

Compensação

Ação corretiva

Mortificação

\section{Explicação}

Em ambos os casos, a responsabilidade pelo ato é evitada, quer porque o sujeito não é responsável ou porque outra pessoa foi especificamente identificada como responsável. O silêncio em relação aos impactos também pode ser visto como uma variação de negação.

$\mathrm{O}$ ato ofensivo foi realizado em resposta a outro ato ofensivo. Como resultado, o provocador deve ser responsabilizado e não o sujeito. Tal explicação pode surgir em relatos de conflitos sindicato-empresa, por exemplo.

A responsabilidade não pode ser atribuída, pois a falta de informação, vontade ou capacidade de parte do sujeito implicaria em injustiça em sua responsabilização.

A responsabilidade é reduzida devido à falta de controle sobre o ato ofensivo.

Embora o resultado do ato seja negativo, os motivos do sujeito podem ter sido bons e o resultado não poderia ter sido antecipado.

O sujeito pode fornecer informações sobre outros aspectos de seu comportamento ou caráter que são positivos e, portanto, estão em contraste com o evento negativo.

O impacto do evento negativo pode ser minimizado, embora a responsabilidade seja reconhecida.

$\mathrm{O}$ ato ofensivo particular distingue-se de outros atos do tipo. Embora possa haver, por exemplo, um incidente de poluição, este não é o tipo de incidente que seria considerado sério. A organização em questão também pode ser diferenciada de outras que são menos "boas".

$\mathrm{O}$ contexto em que o ato ofensivo emerge é redefinido ou uma racionalização para a ação é oferecida, para que a ofensa seja transcendida. Por exemplo, alcançar um retorno financeiro em um contexto comercial competitivo pode ser usado para explicar a demissão de funcionários.

A intensidade do ato pode ser reduzida se for possível criar uma impressão de que o acusador seja de alguma forma responsável ou merece o que aconteceu. Narrativas sobre a irresponsabilidade de, por exemplo, trabalhadores ou comunidades locais podem ser usadas. Em Bhopal, as moradias no entorno das instalações químicas e as falhas do governo em remover favelas do local foram sugeridas como fatores que contribuíram para o número de mortos, razões que foram vistas como fora do controle da Union Carbide e, portanto, deveriam reduzir o impacto do ato ofensivo do vazamento de gás.

Embora a intensidade do ato não seja contestada, o sujeito reduz seu impacto ao oferecer compensações aos afetados. Por exemplo, o investimento em programas comunitários em áreas afetadas por atividades corporativas pode ser usado para aumentar a reputação.

Ação corretiva é prometida para melhorar o impacto do ato ofensivo ou ações são tomadas para garantir que tal não ocorra novamente. Pode ou não incluir a aceitação da responsabilidade do ato.

A responsabilidade é reconhecida, assim como a ofensividade do ato, e o sujeito pede perdão.

Quadro 2. Tipologia de restauração de imagem de Benoit

Fonte: Bebbington, Larrinaga e Moneva (2008, p. 343) com base em Benoit (1995, p.74-79). 


\section{METODOLOGIA}

A estratégia de pesquisa adotada é um estudo de caso, selecionado como um "caso de alto impacto" do fenômeno de interesse, alta significância do problema e para a sociedade (Patton, 2015, p.274). A análise dos dados foi elaborada com base em análise de conteúdo dos relatórios corporativos de sustentabilidade anuais de 2010 a 2014 e bianual de 2015/2016, com a utilização do software Iramuteq® que realiza uma análise lexical de um conjunto de palavras por contexto (Camargo \& Justo, 2013), tornando possível visualizar a tendência de discurso dos relatórios.

Foram efetuadas análises quantitativas de dados textuais, por meio do método de classificação hierárquica descendente (CHD) e análise léxica, fornecendo contextos (classes lexicais) e classes de discurso caracterizadas pelo vocabulário estudado e pelos segmentos de textos que compartilharam esse vocabulário. O corpus de estudo foi constituído a partir de cada um dos seis relatórios analisados. O material foi dividido em unidades de contextos elementares (UCE), segmentos de textos em torno de três linhas que compartilharam as mesmas palavras, permitindo identificar as dimensões e/ou categorias emergentes dentro de cada classe.

As palavras na CHD foram selecionadas pela sua significância (p), frequência (\%) e pelos valores de quiquadrado $\left(\mathrm{Q}^{2}\right)$ mais elevados na classe. O nível de significância representa a probabilidade máxima de erro que se tem ao rejeitar uma hipótese. Todas as palavras selecionadas tinham um $p<0,001$, indicando uma associação significativa. A frequência referente ao conteúdo é a ocorrência da palavra nos segmentos de texto da classe em relação à ocorrência no corpus. $\mathrm{O}$ teste $\mathrm{Q}^{2}$ foi utilizado para verificar a associação da UCE com determinada classe, portanto, quanto mais alto o seu valor, maior a associação.

A análise de conteúdo buscou identificar os principais termos de divulgação e os elementos de reputação presentes, com base em rankings de reputação empresarial apresentados na seção 2.2: desempenho financeiro; qualidade da gestão; desempenho socioambiental; qualidade dos funcionários; e qualidade dos bens e serviços, dividindo-se a análise em relatórios anteriores ao rompimento da barragem de Fundão e posterior ao desastre.

Adicionalmente, foi aplicada a tipologia de restauração de imagem desenvolvida por Benoit (1995), ao relatório da Samarco de 2015/2016, conforme estrutura apresentada no referencial teórico (Quadro 2).

\section{APRESENTAÇÃO E ANÁLISE DOS RESULTADOS}

A Samarco Mineradora S.A. é uma empresa brasileira de mineração, de capital fechado, controlada em partes iguais por dois acionistas: a BHP Billiton Brasil Ltda., empresa de origem anglo-australiana, e a Vale S.A., empresa privatizada brasileira. Seu principal produto são pelotas de minério de ferro, comercializadas para a indústria siderúrgica mundial. A empresa é essencialmente exportadora e, com vistas a ilustrar o seu alcance, em 2012, vendeu sua produção para siderúrgicas de 25 países da América, Ásia, África, Europa e Oriente Médio (Samarco, 2012).

Além da breve caracterização da empresa, a análise está dividida em dois tópicos: 1) análise léxica do conteúdo dos relatórios e dos elementos de reputação presentes no discurso dos relatórios; e 2) análise do discurso contido nos relatórios, à luz da tipologia de estratégias de restauração de imagem desenvolvida por Benoit (1995).

\subsection{Análise dos elementos de reputação nos relatórios de sustentabilidade da Samarco}

Para a análise de conteúdo com o auxílio do software Iramuteq ${ }^{\circledR}$, é necessário identificar cada indivíduo e seu discurso. Cada relatório de sustentabilidade da amostra foi identificado individualmente e definidas seis variáveis para uso do software (relatórios de sustentabilidade de 2010; 2011; 2012; 2013; 2014 e 2015/2016).

O corpus geral foi constituído pelas seis variáveis (relatórios), separado em 6.218 segmentos de texto (ST), com aproveitamento de 5.217 ST, perfazendo 83,9\% do total. Emergiram 219.977 palavras, formas ou vocábulos, sendo 12.057 palavras distintas, dentre elas, 4.140 com uma única ocorrência.

O conteúdo foi categorizado em três classes de discurso, conforme a maior proximidade identificada pelo programa. As classes apresentam um grau de associação com os relatórios, estabelecido por meio do cálculo do qui-quadrado $\left(\mathrm{Q}^{2}\right)$ e foram denominadas com base nos termos que sobressaíram na análise textual, conforme sumarizado na Tabela 1. 
Tabela 1. Relação entre classe e ano do relatório

\begin{tabular}{clcc}
\hline Classe & \multicolumn{1}{c}{ Nome da classe } & Ano do relatório & $\mathbf{Q}^{2}$ de associação com a classe \\
\hline \multirow{2}{*}{1} & \multirow{2}{*}{ Ênfase na gestão } & 2012 & 15,82 \\
& & 2013 & 10,45 \\
\multirow{2}{*}{2} & \multirow{2}{*}{ Ênfase nos laços com a sociedade } & 2014 & 8,25 \\
\multirow{2}{*}{3} & Ênfase na produção & $2015 / 2016$ & 123,92 \\
& & 2010 & 38,75 \\
& & 2011 & 12,47 \\
\hline
\end{tabular}

Fonte: dados da pesquisa.

\subsubsection{Análise dos elementos de reputação nos relatórios anteriores ao rompimento da barragem}

Neste tópico são analisadas as classes de discurso 1 e 3 dos relatórios de sustentabilidade anteriores ao rompimento da barragem, em relação à ocorrência de palavras e aos cinco elementos de reputação. Para obedecer a ordem cronológica dos relatórios, são apresentados os resultados para as classes 3 e 1, nessa ordem.

A classe 3 - ênfase na produção - está mais ligada aos relatórios de sustentabilidade dos anos de 2010 e 2011, tendo como palavras de destaque "água" $\left(Q^{2}=318,32\right)$, "tonelada" $\left(Q^{2}=241,6\right)$, "milhão" $\left(Q^{2}=240,41\right)$, "minério" $\left(Q^{2}=217,82\right)$, "rio" $\left(Q^{2}=216,94\right)$, "germano" $\left(Q^{2}=207,62\right)$, além das palavras "emissão", "rejeito", "usina", "energia", "pelotas", "ferro", "gás", "consumo" e "resíduo". Percebe-se que o discurso recorrente esteve voltado à produção e à divulgação das estratégias de sustentabilidade como foco para alavancagem da reputação e consequente melhoria da percepção de imagem.

O discurso está alinhado à crescente exportação do minério de ferro e produção ascendente pela qual passava a empresa. Foi recorrente o uso das palavras "produção" e "usina" nos relatórios, exaltando a expansão da produção, com a inauguração de uma nova usina de pelotização, acrescida de ganhos de produtividade, alavancando o desempenho financeiro. Também as palavras "ferro" e "pelotas" foram destacadas no discurso, dando ênfase nos ganhos de produção das mesmas e na qualidade de bens e serviços.

O elemento desempenho socioambiental foi relevante nos relatórios da classe 3, tendo a palavra "água" assumido grande destaque, uma vez que os referidos relatórios demonstraram as ações da empresa em reutilizar a água em seus processos, bem como devolvê-la em condições próprias ao ecossistema, além das palavras "resíduos" e "emissão", também apresentadas dentro desse mesmo contexto. No entanto, não houve uma ênfase específica nos relatórios para a qualidade da gestão ou qualidade dos empregados.

O Quadro 3 relaciona os elementos da reputação e as palavras recorrentes no discurso dos relatórios de 2010-2011, relacionados à classe 3, com ênfase na produção.

\begin{tabular}{ll}
\hline Elementos da Reputação & Palavras recorrentes nos relatórios da classe 3 \\
\hline Desempenho financeiro & Produção e usina \\
Qualidade da gestão & ----- \\
Qualidade dos empregados & ----- \\
Desempenho socioambiental & Água, resíduos e emissão \\
Qualidade de bens e serviços & Ferro e pelotas \\
\hline
\end{tabular}

Quadro 3. Elementos da reputação e palavras recorrentes - discurso classe 3

Fonte: dados da pesquisa.

Na classe 1 - ênfase na gestão - predominaram as palavras "risco" $\left(Q^{2}=219,48\right)$; "negócio" $\left(Q^{2}=213,51\right)$, "empregado" $\left(Q^{2}=206,64\right)$, "gestão" $\left(Q^{2}=203,43\right)$, seguidas por outras como "conduta"; "comunicação", "sustentabilidade", "conformidade", "reputação", "empresa", "estratégico", "prático", "segurança", "modelo", "saúde", "visão", "cliente", "mercado" e "desempenho".

Pode-se observar uma predominância do discurso em torno da qualidade da gestão da empresa e sua interação com stakeholders e a geração de valor, tendo em vista a atividade fim da Samarco de extração de minérios e a queda do preço da commodity no mercado internacional, reforçando assim o discurso voltado para a gestão e o compromisso em agregar valor. 
O Quadro 4 relaciona os elementos da reputação e as palavras recorrentes no discurso dos relatórios de 2012 a 2014, relacionados à classe 1 - ênfase na gestão.

\begin{tabular}{ll}
\hline Elementos da Reputação & Palavras recorrentes nos relatórios da classe 1 \\
\hline Desempenho financeiro & Negócio \\
Qualidade da gestão & Gestão \\
Qualidade dos empregados & Empregado \\
Desempenho socioambiental & Conduta, sustentabilidade, risco e conformidade \\
Qualidade de bens e serviços & Estratégico \\
\hline
\end{tabular}

Quadro 4. Elementos da reputação e palavras recorrentes - discurso classe 1

Fonte: dados da pesquisa.

\subsubsection{Análise dos elementos de reputação do relatório posterior ao rompimento da barragem}

Em relação à classe 2 - ênfase nos laços com a sociedade - associada ao relatório de 2015/2016, verifica-se que o discurso está intimamente ligado ao rompimento da barragem de Fundão, tendo como palavras predominantes, "comunidade" $\left(Q^{2}=677,09\right)$, "local” $\left(Q^{2}=356,91\right)$, público $\left(Q^{2}=261,7\right)$, "fundação" $\left(Q^{2}=207,29\right)$, "Renova" $\left(Q^{2}=174,16\right)$, além das palavras "rompimento", "reparação", “diálogo", "educação", "renda”, "obra", “economia”, "estadual”, "municipal”, "social”, “contratação”, “emprego”, "população" e "programa”.

As palavras sugerem iniciativa da empresa de se mostrar socialmente apta e disponível para reparar os danos causados, além da importância social de seu funcionamento. A classe 2 apresenta, portanto, um contexto de preocupação social da empresa estudada, demonstrando suas ações sociais com as comunidades próximas à região de atuação da empresa e a proposta de recuperação ambiental e proteção de áreas florestais.

\begin{tabular}{ll}
\hline Elementos da Reputação & Palavras recorrentes nos relatórios da classe 2 \\
\hline Desempenho financeiro & Economia e contribuição \\
Qualidade da gestão & Fundação Renova, reparação e diálogo \\
Qualidade dos empregados & Educação \\
Desempenho socioambiental & Comunidade, obra e rompimento \\
Qualidade de bens e serviços & ----- \\
\hline
\end{tabular}

Quadro 5. Elementos da reputação e palavras recorrentes - discurso classe 2 Fonte: dados da pesquisa.

No que tange ao item de reputação desempenho financeiro, percebe-se no discurso o esforço da Samarco em demonstrar que, apesar dos resultados financeiros negativos nos anos de 2015 e 2016, justificados pelo rompimento da barragem de Fundão, a empresa possuía reservas financeiras suficientes para cobrir todo o passivo socioambiental, bem como capacidade futura para retomar suas operações, em função do potencial de suas minas de exploração de minério de ferro e, assim, gerar resultados positivos para seus stakeholders financeiros, o que demonstra a presença desse elemento, no sentido de gerenciar os riscos à reputação.

Uma das declarações da Samarco $(2016$, p.35) confirma resultados positivos e volumes de produção superiores ao período anterior: "aumento de 1,5\% em relação ao ano anterior (25,075 milhões de toneladas), apesar dos impactos decorrentes da paralisação das operações de Germano e de Ubu.". A Samarco também comunicou a transferência de recursos realizada pelas controladoras (BHP e Vale) para garantir o fluxo de caixa necessário para fazer frente aos desembolsos previstos, bem como a necessidade da retomada operacional. Nesses trechos, a empresa se apresenta como financeiramente capaz de fazer frente aos seus compromissos socioambientais, além de deixar implícita a sua capacidade para a retomada das atividades e geração de receitas.

A qualidade da gestão está associada aos discursos presentes nas classes 1 (relatórios de 2012 a 2014) e na classe 2 (relatório bianual 2015/2016), sugerindo que a Samarco já tinha preocupação em demonstrar a qualidade de sua gestão antes do acidente, mudando, porém, o enfoque. Em 2015/2016, a qualidade da gestão passa a fazer parte da estratégia de demonstrar sua capacidade em lidar com as consequências do acidente. 
O relatório de sustentabilidade do biênio 2015/2016 foi aberto por uma mensagem da presidência da empresa que destaca o compromisso constante em reparar os danos e a capacidade que a empresa tem de realizar tal reparação. A empresa ressaltou os riscos enfrentados por conta da tragédia ocorrida, inclusive os riscos à reputação, mas buscando transmitir sua capacidade de ultrapassar tais desafios:

2015 foi o ano em que a Samarco vivenciou, na prática, os impactos da materialização de um dos principais riscos do negócio: o rompimento de uma barragem de rejeitos. Esse fato acabou se revelando uma tragédia ambiental que marcou a história da Samarco, exigindo, assim, enorme capacidade de resposta e expondo a Empresa a uma série de outros riscos, relacionados à reputação, às licenças de operação e à sua própria continuidade.

O modelo de gestão de riscos construído pela Samarco adota práticas de referência de mercado (baseado no modelo Enterprise Risk Management - ERM), do Committee of Sponsoring Organizations of the Treadway Commission (COSO), e diretrizes dos acionistas Vale S.A. e BHP Billiton Brasil. A Política de Gestão de Riscos e o seu manual estabelecem os critérios de avaliação e monitoramento dos riscos. (Samarco, 2016, p. 15, grifo nosso).

A própria empresa explicita a preocupação com a gestão de riscos, em especial os que se referem à sua reputação, numa clara demonstração da influência do gerenciamento de riscos no relatório de sustentabilidade.

Em relação ao desempenho socioambiental, o relatório de sustentabilidade posterior ao acidente teve a preocupação constante de retratar a Samarco como uma empresa socialmente responsável, de forma a fortalecer tal percepção junto aos diversos stakeholders, seguindo a afirmação de Bebbington, Larrinaga e Moneva (2008) de que as empresas, ao focarem na responsabilidade socioambiental, destacam o seu desempenho com vistas a gerenciar a sua reputação.

Diante da destruição causada pelo rompimento da barragem, a Samarco (2016, p.37) buscou divulgar informações que destacassem seu comprometimento com a sociedade e meio ambiente em que atua, destacando investimentos em tecnologia e eficiência, racionalização de recursos naturais e "a conformidade e a evolução contínua na área ambiental como um caminho para assegurar a perenidade dos negócios". Relatou que, em 2015 até o acidente, foram aplicados mais de R \$45 milhões em projetos ambientais e destacou que "os maiores gastos foram em efluentes industriais e água, na unidade de Ubu, e no prolongamento do quarto extravasor e no extravasor auxiliar da barragem de Fundão, além do sistema de drenagens internas e de ombreiras, na unidade de Germano", ou seja, itens críticos nas causas do acidente. Também informou que após o acidente a empresa "voltou-se à execução de ações de prevenção, monitoramento e mitigação dos impactos emergenciais decorrentes do rompimento."

Outro ponto bastante presente no relatório é a forma como a Samarco vem lidando com a reparação da tragédia ambiental, mostrando seu comprometimento e sua responsabilidade, tendo criado a Fundação Renova para fazê-lo, sucedendo a própria Samarco no papel de responsável pelas reparações. Admitiu que o rompimento da barragem gerou impactos ao meio ambiente, em Minas Gerais e Espírito Santos, sobre a "biodiversidade aquática e terrestre, qualidade da água de corpos hídricos, assoreamento de rios, estuários e manguezais na foz do rio Doce e unidades de conservação, foram identificados e são abrangidos pelo Termo de Transação e de Ajustamento de Conduta (TTAC).” Comentou a contratação de empresa visando providências e planos (Samarco, 2016, p. 78).

No que tange à qualidade dos empregados, Arora e Lodhia (2017) afirmam que as divulgações na comunicação corporativa sobre a qualidade da mão-de-obra, bem como na constante capacitação do quadro funcional, são utilizadas para tirar o foco dos problemas vivenciados. No relatório de sustentabilidade da Samarco do biênio 2015/2016, existe uma seção inteira dedicada ao constante aprimoramento do quadro funcional e sua preocupação em conter o desastre ocorrido. "A seguir, é apresentado trecho do relatório que aponta nessa direção.

O modelo de gestão de pessoas da Samarco é balizado pelos valores e pela cultura organizacional e orientado por pesquisas de Clima, Cultura e Reputação, usadas para definir políticas que melhorem o ambiente de trabalho e assegurem a competitividade do negócio (grifo nosso).

Um aspecto que a empresa deixa claro no relatório é a preocupação de que seu relacionamento com os empregados seja pautado em reputação, o que mais uma vez demonstra que a empresa tem uma preocupação constante com o tema e da utilização do relatório social como um instrumento de gestão de riscos à reputação.

Em relação à qualidade dos bens e serviços, foi destacada a importância dos bens produzidos para a economia do país, sendo a empresa uma das maiores exportadoras de minério de ferro brasileiro. A empresa ressaltou a opinião popular de que as operações deveriam ser retomadas, devido à sociedade entender ser muito importante a atividade desempenhada, destacando suas providências para retomada operacional (Samarco, 2016, p. 29). 


\subsection{Aplicação da tipologia de Benoit}

As ações empreendidas pela Samarco para recuperação dos danos causados foram o ponto forte da divulgação do relatório de sustentabilidade após o acidente. Ressalta-se a falta de divulgação de um relatório anual de sustentabilidade no ano de 2015, tendo a empresa optado por divulgar o relatório bienal 2015/2016 com dados agregados. Uma possível justificativa para esse fato diz respeito à imagem, o que foi analisado utilizando-se a tipologia de estratégias de restauração de imagem desenvolvida por Benoit (1995), conforme se vê no Quadro 6.

\begin{tabular}{|c|c|c|}
\hline Estratégia & Explicação & Trechos de discursos dos relatórios de sustentabilidade \\
\hline \multirow{7}{*}{ Compensação } & \multirow{7}{*}{$\begin{array}{l}\text { Embora a intensidade do ato } \\
\text { não seja contestada, o sujeito } \\
\text { reduz seu impacto ao oferecer } \\
\text { compensações aos afetados. }\end{array}$} & $\begin{array}{l}\text { Com o apoio da BHP Billiton e da Vale, a Samarco se } \\
\text { mobilizou, desde o rompimento da barragem de Fundão, para } \\
\text { prestar assistência às comunidades impactadas, para reinstalar } \\
\text { a população desabrigada, apoiar a busca por desaparecidos e } \\
\text { prestar esclarecimentos às autoridades e ao poder público } \\
\text { (Samarco, 2016, p. 68). }\end{array}$ \\
\hline & & $\begin{array}{l}\text { Realocação daqueles que perderam seus lares, distribuição } \\
\text { de água potável e mineral, resgate de animais, atendimento } \\
\text { psicossocial e restabelecimento de acessos danificados, entre } \\
\text { outros, foram as frentes de trabalho da ação emergencial } \\
\text { (Samarco, 2016, p. 68). }\end{array}$ \\
\hline & & $\begin{array}{l}\text { As famílias que perderam suas residências foram instaladas em } \\
\text { casas ou acomodações (Samarco, 2016, p. 68). }\end{array}$ \\
\hline & & $\begin{array}{l}835 \text { hectares revegetados emergencialmente nos municípios de } \\
\text { Mariana, Barra longa, rio doce e Santa Cruz do Escalvado, a fim } \\
\text { de controlar processos de erosão e carreamento de sólidos com } \\
\text { as chuvas (Samarco, 2016, p. } 68 \text { ). }\end{array}$ \\
\hline & & $\begin{array}{l}818 \text { alunos das comunidades impactadas na região de Mariana } \\
\text { e barra longa concluíram o ano letivo de } 2015 \text { e iniciaram o ano } \\
\text { letivo de } 2016 \text { em dia, conforme o calendário escolar (Samarco, } \\
2016, \text { p. 68). }\end{array}$ \\
\hline & & $\begin{array}{l}\text { A Samarco promoveu a limpeza e a reforma de escolas, imóveis } \\
\text { (residenciais e comerciais), áreas públicas e está realizando } \\
\text { a dragagem dos rejeitos retidos no reservatório da usina } \\
\text { Hidrelétrica Risoleta Neves (Candonga). Nove pontes de acesso } \\
\text { às comunidades foram reconstruídas e liberadas para tráfego, } \\
\text { uma a cada } 15 \text { dias (Samarco, 2016, p. } 71 \text { ). }\end{array}$ \\
\hline & & $\begin{array}{l}\text { A Samarco assistiu } 5.639 \text { animais de novembro de } 2015 \text { a julho } \\
\text { de 2016. Animais de grande porte foram encaminhados para } \\
\text { fazendas de Mariana e Acaiaca (Samarco, 2016, p. } 72 \text { ). }\end{array}$ \\
\hline \multirow[b]{2}{*}{ Ação Corretiva } & \multirow{2}{*}{$\begin{array}{l}\text { Ação corretiva é prometida } \\
\text { para melhorar o impacto do ato } \\
\text { ofensivo ou ações para garantir } \\
\text { que tal não ocorra novamente. }\end{array}$} & $\begin{array}{l}\text { As barragens foram construídas em linha com a política nacional } \\
\text { de Segurança de barragens (lei 12.334/2010), com inspeções de } \\
\text { segurança próprias e equipes de operação em turno de } 24 \text { horas, } \\
\text { para manutenção e monitoramento (Samarco, 2016, p. 64). }\end{array}$ \\
\hline & & $\begin{array}{l}\text { Buscando atender às diretrizes da Defesa Civil e do Corpo de } \\
\text { Bombeiros e visando à redução de riscos, a empresa adotou } \\
\text { medidas adicionais e iniciou obras nas barragens para garantir } \\
\text { a segurança das estruturas remanescentes e conter o fluxo de } \\
\text { rejeitos (Samarco, 2016, p. 64). }\end{array}$ \\
\hline Mortificação & $\begin{array}{l}\text { A responsabilidade é reconhecida, } \\
\text { assim como a ofensividade do ato } \\
\text { e o sujeito pede perdão. }\end{array}$ & $\begin{array}{l}\text { Mais uma vez, lamento profundamente pelas vidas que foram } \\
\text { perdidas (Samarco, 2016, p. 7). }\end{array}$ \\
\hline
\end{tabular}

Quadro 6. Tipologia de Benoit aplicada ao relatório de 2015/2016

Fonte: dados da pesquisa. 
O discurso presente no relatório de sustentabilidade de 2015/2016 foi permeado por mecanismos para restauração de imagem previstos na tipologia desenvolvida por Benoit (1995), corroborando a ideia de utilização do relatório como parte dos processos de RRM. Assim, com base nos cinco elementos inerentes à reputação e nas estratégias de restauração de imagem propostas por Benoit (1995), verifica-se a influência de elementos do RRM, sugerindo o uso do disclosure socioambiental como ferramenta de gerenciamento de riscos à reputação, especialmente durante um momento de crise.

\section{CONCLUSÃO}

O objetivo desta pesquisa foi investigar a influência do reputation risk management sobre o disclosure de relatórios corporativos, em especial dos relatórios de sustentabilidade. A pesquisa foi desenvolvida por meio da análise dos relatórios de sustentabilidade da mineradora Samarco, responsável pelo desastre da barragem de Fundão, tendo como arcabouço teórico o RRM e a teoria da legitimidade.

Da análise dos relatórios, foi possível estabelecer ligação entre o disclosure socioambiental e os processos de RRM, conforme referencial teórico, em que se confrontam os discursos dos relatórios de sustentabilidade com os elementos de reputação e a tipologia de restauração de imagem. Os resultados são condizentes com as pesquisas no que diz respeito ao disclosure como ferramenta de RRM e, sobretudo, após um evento negativo de grandes proporções. Foram encontradas evidências de preocupação com a reputação em todos os relatórios analisados da Samarco. Interessante notar que, por meio da análise de conteúdo, foi possível traçar um paralelo com a evolução da empresa e ambiente de negócios ao longo dos anos do período estudado, culminando no acidente e gestão do mesmo.

Pesquisas têm mostrado que a busca pela manutenção do contrato social tem produzido impacto nos relatórios emitidos pelas empresas após a ocorrência de um acidente ambiental. No caso da Samarco, a análise qualitativa de seu relatório de sustentabilidade do biênio 2015/2016, posterior ao desastre, comparativamente aos relatórios de 2010 a 2014, demonstra a mudança no foco do discurso.

Além disso, a análise de dados permitiu inferir que, durante um evento negativo em que há um grande estrago na reputação de uma empresa, o disclosure será realizado para legitimar sua existência, além de coadunar com a ideia levantada ao longo do artigo de que a reputação e seu gerenciamento nos momentos de crise é o fator preponderante na divulgação, mais do que a legitimidade, uma vez que essa é adquirida no longo prazo. Do estudo, pode-se verificar que a ótica do RRM traz uma compreensão mais ampla sobre o disclosure, mas não inviabiliza as explicações baseadas na teoria da legitimidade, uma vez que esses referenciais são de difícil separação e caminham em uma mesma direção.

A presente pesquisa traz contribuições na área de estudo nas dimensões teórica, metodológica e prática. $\mathrm{Na}$ primeira, é trazido um olhar mais apurado para identificar os fatores determinantes do disclosure socioambiental, ampliando o espectro da teoria da legitimidade, acrescentando-se a componente reputação e o gerenciamento dos riscos sobre a reputação como fator intermediário no alcance/manutenção/reparo da legitimidade. Em relação à contribuição metodológica, a presente pesquisa aplicou um método de análise esquemático, que permitiu maior objetividade na análise de conteúdo e comparação dos resultados com a teoria de base. A contribuição prática trazida vai no sentido de que a compreensão da medida em que os relatórios socioambientais são capazes de influenciar a reputação pode encorajar mais organizações a divulgá-los (em maior quantidade e com maior qualidade).

No que tange às limitações da pesquisa, aponta-se a subjetividade inerente ao método de análise adotado, que pode exigir inferência dos pesquisadores em suas diferentes fases. Também é relevante mencionar a complexidade em se determinar como o RRM influencia as estratégias de divulgação dos relatórios corporativos no caso apresentado, haja vista a dificuldade de se encontrar informações, predominantemente confidenciais, sobre esse tipo de gerenciamento de fora da empresa, tendo a pesquisa se baseado nos relatórios externos publicados. Outro ponto a ser destacado é o fato de o rompimento da barragem de Fundão ter acontecido em data próxima ao desenvolvimento desta pesquisa, existindo, portanto, eventos ainda em desenvolvimento, investigações em andamento, cujos resultados podem impactar a análise realizada.

Como estudos futuros, sugere-se investigar as percepções de reputação dos gerentes e estudar os processos internos de relato e engajamento de stakeholders, bem como a maneira pela qual a função de elaboração de relatórios está vinculada a outros aspectos das operações, tais como a tomada de decisão e planejamento de uma organização, que podem contribuir para a sua reputação. Também é importante expandir o estudo de reputação e disclosure utilizando uma amostra maior de empresas em setores econômicos diversos. 
Enquanto este artigo estava em elaboração, novo rompimento de barragem, da mineradora Vale - sócia da Samarco - ocorreu em Brumadinho-MG. Esse acidente devastador deixou 240 mortos e 32 desaparecidos. Na sequência, vários casos de risco de rompimento de barragens foram noticiados, a exemplo do município de Barão de Cocais-MG, quando a população da cidade chegou a ser evacuada. Tais ocorrências ratificam a relevância de pesquisas acadêmicas no setor de mineração, incluindo regulamentação, fiscalização e disclosure voluntário e obrigatório.

\section{REFERÊNCIAS}

Arora, M. P., \& Lodhia, S. (2017). The BP Gulf of Mexico oil spill: Exploring the link between social and environmental disclosures and reputation risk management. Journal of Cleaner Production, 140(3), 12871297. DOI: https://doi.org/10.1016/j.jclepro.2016.10.027.

Bebbington, J, Larrinaga, C., \& Moneva, J. M. (2008). Corporate social reporting and reputation risk management. Accounting, Auditing \& Accountability Journal, 21(3), 337-361. DOI: https://doi. org/10.1108/09513570810863932.

Benoit, W.L. (1995). Accounts, Excuses and Apologies: A Theory of Image Restoration Strategies. New York: State University of New York Press.

Bice, S. (2014). What Gives You a Social Licence? An Exploration of the Social Licence to Operate in the Australian Mining Industry. Resources, 3(1), 62-80. DOI: https://doi.org/10.3390/resources3010062.

Camargo, B. V., \& Justo, A. M. (2013). IRAMUTEQ: um software gratuito para análise de dados textuais. Temas Psicol. Ribeirão Preto, 21(2).

Cho, C. H. (2009). Legitimation strategies used in response to environmental disaster: A French case study of Total S.A'.s Erika and AZF incidents. European Accounting Review, 18(1), 33-62. DOI: https://doi. org/10.1080/09638180802579616.

Cho, C., Laine, M., Roberts, R. W. \& Rodrigue, M. (2015). Organised hypocrisy, organizational façades, and sustainability reporting. Accounting, Organizations and Society, 40, 78-94. DOI: https://doi.org/10.1016/j. aos.2014.12.003.

Deegan, C. (2002). The legitimating effect of social and environmental disclosures - a theoretical foundation. Accounting, Auditing \& Accountability Journal, 15(3), 281-311. DOI: https://doi. org/10.1108/09513570210435852.

Deegan, C., Rankin, M., \& Tobin, J. (2002). An examination of the corporate social and environmental disclosures of BHP from 1983-1997: a test of legitimacy theory. Accounting, Auditing \& Accountability Journal, 15(3), 312-43. DOI: https://doi.org/10.1108/09513570210435861.

Deephouse, D.L., \& Carter, S.M. (2005). An examination of differences between organizational legitimacy and organizational reputation. Journal of Management Studies, 42(2), 329-60. DOI: https://doi.org/10.1111/ j.1467-6486.2005.00499.x.

Eugenio, T., Lourenço, I. C., \& Morais, A. I. (2010). Recent developments in social and environmental accounting research. Social Responsibility Journal, 6(2), 286-305. DOI: https://doi.org/10.1108/17471111011051775.

Friedman, A.L., \& Miles, S. (2001). Socially responsible investment and corporate social and environmental reporting in the UK: an exploratory study. British Accounting Review, 33(4), 523-548. DOI: https://doi. org/10.1006/bare.2001.0172.

Fombrun, C. (1996). Reputation: Realizing Value from the Corporate Image. Boston: Harvard Business School Press.

Fombrun, C., \& Van Riel, C. (1997). The reputational landscape. Corporate Reputation Review, 1(1-2), 5-13. DOI: https://doi.org/10.1057/palgrave.crr.1540024.

Gray, R., Owen, D.L., \& Adams, C.A. (1996) Accounting and Accountability: changes and challenges in corporate social and environmental reporting. Prentice Hall, London.

Kuruppu, S., \& Milne, M. (2014). Managing reputation and maintaining legitimacy: Understanding a company's responses to sustainability. Working paper, University of Canterbury, NZ. 
Kuruppu S., Milne M., \& Tilt C. (2019). Gaining, maintaining and repairing organisational legitimacy: when to report and when not to report. Accounting, Auditing and Accountability Journal, 32(7), 2062-2087. DOI: https://doi.org/10.1108/AAAJ-03-2013-1282.

Larkin, J. (2003). Strategic Reputation Risk Management. New York, NY: Palgrave Macmillan.

Lozano, R., \& Huisingh, D. (2011). Inter-linking issues and dimensions in sustainability reporting. Journal of Cleaner Production, 19(2-3), 99-107. DOI: https://doi.org/10.1016/j.jclepro.2010.01.004.

Miles, M. P., \& Govin, J. G. (2000). Environmental Marketing: A source of reputational, competitive and financial advantage. Journal of Business Ethics, 23(3), 299-311. DOI: https://doi.org/10.1023/A:1006214509281.

Milne, M. J., \& Patten, D.M. (2002). Securing organizational legitimacy: an experimental decision case examining the impact of environmental disclosures. Accounting, Auditing \& Accountability Journal, 15(3), 372-405. DOI: https://doi.org/10.1108/09513570210435889.

Patten, D. M. (1991). Exposure, legitimacy, and social disclosure. Journal of Accounting and Public Policy, 10(4), 297-308. DOI: https://doi.org/10.1016/0278-4254(91)90003-3.

Patten, D. (1992). Intra-industry environmental disclosures in response to the Alaskan oil spill: a note on legitimacy theory. Accounting, Organizations and Society, 17(5), 471-475. DOI: https://doi.org/10.1016/03613682(92)90042-Q.

Patton, M. Q. (2015). Qualitative Research \& Evaluation Methods (4 ed). Thousand Oaks, CA: SAGE Publications.

Pellegrino, C., \& Lodhia, S. (2012). Climate change accounting and the Australian mining industry: exploring the links between corporate disclosure and the generation of legitimacy. Journal of Cleaner Production, 36, 68-82. DOI: https://doi.org/10.1016/j.jclepro.2012.02.022.

Roberts, P. W., \& Dowling, G. R. (2002). Corporate reputation and sustained superior financial performance. Strategic Management Journal, 23(12), 1077-1093.DOI: https://doi.org/10.1002/smj.274.

Samarco (2011). Relatório Anual de Sustentabilidade 2010. Belo Horizonte.

Samarco (2012). Relatório Anual de Sustentabilidade 2011. Belo Horizonte.

Samarco (2013). Relatório Anual de Sustentabilidade 2012. Belo Horizonte.

Samarco (2014). Relatório Anual de Sustentabilidade 2013. Belo Horizonte.

Samarco (2015). Relatório Anual de Sustentabilidade 2014. Belo Horizonte.

Samarco (2017). Relatório Anual de Sustentabilidade 2015-2016. Belo Horizonte.

Serra, C. (2018). Tragédia em Mariana: a história do maior desastre ambiental do Brasil. Rio de Janeiro: Record.

Suchman, M. (1995). Managing Legitimacy: Strategic and Institutional Approaches. Academy of Management Review, 20(3), 571-610. DOI: https://doi.org/10.2307/258788.

Thomaz, J. C., \& Brito, E. P. Z. (2010). Reputação Corporativa: Construtos Formativos e Implicações para a Gestão. Revista de Administração Contemporânea, 2(14), 229-250. DOI: http://dx.doi.org/10.1590/S141565552010000200004.

Toms, J.S. (2002). Firm resources, quality signals and the determinants of corporate environmental reputation: some UK evidence. British Accounting Review, 34(3), 257-282. DOI: https://doi.org/10.1006/bare.2002.0211.

Unerman, J. (2008). Strategic reputation risk management and corporate social responsibility reporting. Accounting, Auditing \& Accountability Journal, 21(3), 362-364. DOI: https://doi.org/10.1108/09513570810863941.

Wanderley, L. J., Mansur, M. S., Milanez, B., \& Pinto, R. G. (2016). Desastre da Samarco/Vale/BHP no Vale do Rio Doce: aspectos econômicos, políticos e socio ambientais. Ciência e Cultura, 68(3), 30-35. DOI: http:// dx.doi.org/10.21800/2317-66602016000300011.

Wink, P. K. S. (2012). Reação aos acidentes ambientais: evidências em uma empresa de mineração do mercado brasileiro. Dissertação (Mestrado em Ciências Contábeis), Centro de Ciências Sociais Aplicadas da Universidade Federal de Pernambuco, Recife, Pernambuco, Brasil.

\section{Como citar este artigo}

Oliveira, J. A. N de, \& Cintra, Y. C. (2019). Gerenciamento de riscos à reputação no discurso dos relatórios corporativos da Samarco. Revista de Contabilidade e Organizações, 13:e158709. DOI: http://dx.doi. org/10.11606/issn.1982-6486.rco.2019.158709 